\section{Resilience and professional quality of life in staff working with people with intellectual disabilities and offending behavior in community based and institutional settings}

\section{Erik Sondenaa,1,2 Christian Lauvrud, Marita Sandvik,3 Kåre Nonstad,1 Richard Whittington 1,4}

1St. Olavs University Hospital, Forensic Department, Broset, Trondheim, Norway; 2University College of Sor-Trondelag, Department of Social Education, Trondheim, Norway; ${ }^{3 S t}$. Olavs University Hospital, Forensic Unit for Offenders with Intellectual Disabilities, Broset, Trondheim, Norway; ${ }^{4}$ University of Liverpool, Institute of Psychology, Health and Society, Health \& Community Care Research Unit, Liverpool, UK

\section{Abstract}

Staff in forensic services for people with intellectual disabilities (ID) are expected to deal with a wide range of emotional challenges when providing care. The potential impact of this demanding work has not been systematically explored previously. This article explores the professional quality of life (QoL) and the resilience (hardiness) of the staff in this setting. The Professional QoL questionnaire and the Disposional Resilience Scale were completed by staff ( $\mathrm{n}=85,80 \%$ response rate) in the Norwegian forensic service for ID offenders. Responses from staff working in institutional settings were compared to those from staff in local community services. Staff in the local community services had higher resilience scores compared to the staff in the institutional setting, $\quad(\mathrm{t}=2.19 ; \quad \mathrm{P}<0.05)$. However in the other QoL and resilience domains there were no differences between the staff in the two settings. The greater sense of resilient control among community staff may be a function of both the number of service users they work with and the institutional demands they face. Even though these participants worked with relatively high risk clients, they did not report significantly impaired quality of life compared to other occupations.

\section{Introduction}

Recent national surveys have indicated that staff providing care for people with intellectual disabilities faces a high risk of exposure to violence at work. 1,2 Violence and threats are common and $50 \%$ of all staff report being exposed to one or more episodes during the last year. ${ }^{2}$ The complex and demanding management of violent service users often provokes adverse feelings and contributes to a negative working experience. ${ }^{3}$ It often also causes feelings of fear and anxiety. 4

People with intellectual disabilities (ID) who are also offenders are some of the most difficult health service users to treat and historically they have also received little attention from researchers or the wider society. 5 The research that has been conducted has concentrated on offenders with mild ID within secure placements. Offenders with a moderate or more severe level of ID seldom enter the criminal justice system (CJS), as they are diverted into mental health services, ID services, or forensic mental health services. As a result, there is a dearth of studies exploring the needs and living conditions of offenders with moderate ID compared with offenders with mild ID.

Offenders with ID have many characteristics in common with offenders in the general population.6,7 They tend to be young and male and have experienced social disadvantage, unstable environments, and financial instability. ${ }^{8}$ There is little research on how the characteristics of people with ID who are labeled offenders may differ from those with ID who do not offend. ${ }^{9}$ Holland et al. ${ }^{7}$ proposed that two groups of offenders with ID can be distinguished according to whether they are known to the ID services. Amongst the smaller group who are known to services the term offence may often be confused with challenging behavior. ${ }^{10}$

The Norwegian system has quite restrictive policies regarding diversion of offenders with ID from the criminal justice system. There has been some focus on intellectual impairment among offenders, 11 but the government's priorities are focused elsewhere on, for instance, building more prison accommodation, encouraging multidisciplinary cooperation in preventing recidivism, developing alternatives to imprisonment alongside better rehabilitation services and evidence-based research. 12

Norway's new penal code from 2002, Mandatory care established stringent criteria for bringing people with ID into the forensic services. ${ }^{13}$ These include the commission of a serious or life-threatening crime by a person defined as non-responsible due to ID with a level of intellectual functioning corresponding to moderate or severe ID (IQ<55). The risk of reoffending must also be regarded as significant before a sentence can be imposed. Offenders who do not fulfill these criteria are given standard prison sentences with no access to ID specific services.
Correspondence: Erik Søndenaa, St. Olavs University Hospital, Forensic dep. Brøset, Postbox 1803, Lade, 7440 Trondheim, Norway.

Tel. +47.992.44771.

E-mail: erik.sondenaa@ntnu.no

Key words: resilience, professional quality of life, health-care staff, intellectual disability offenders.

Acknowledgements: the authors wish to thank the office workers Bodil Stenkløv and Irene Wirkola for their valuable contribution in collecting and loading of the data.

Contributions: ES, CL, MS and KN conceived and designed the study. ES and MS collected the data. ES, CL and RW performed the statistical analysis and drafted the manuscript.

Conflict of interests: the authors declare no potential conflict of interests.

Received for publication: 16 0ctober 2012 .

Revision received: 12 November 2012.

Accepted for publication: 13 November 2012.

This work is licensed under a Creative Commons Attribution NonCommercial 3.0 License (CC BYNC 3.0).

(C) Copyright E. Søndenaa et al., 2013 Licensee PAGEPress, Italy

Health Psychology Research 2013; 1:e3 doi:10.4081/hpr.2013.e3

\section{Psychological vulnerabilities} of staff working with intellectually disabled offenders

Work-related stress may occur when the perceived demands of the job exceed an individual's resources to cope and do the job. 14 The stressors typically reported by intellectual disability support staff include challenging behavior, 15 interpersonal issues with colleagues and organizational concerns (e.g. inadequate staffing). 16,17

Professional quality of life as conceptualized by Stamm incorporates both positive and negative aspects. 18 The negative aspect includes both burnout symptoms and secondary traumatic stress. While the incidence of developing problems associated with the negative aspects of providing care seems to be low, they can be serious and can affect the individual, their close relationships, the care that they provide, and their organizations. 18

Burnout is a psychological syndrome that can occur in response to chronic, uncontrollable work demands when providing a service to people in some way. ${ }^{19}$ It is most common in workers who give of themselves emotionally and especially when they give out more than they get back.19,20 The quality of services with fewer positive interactions and less staff con- 
tact has been found to be correlated to staff burnout symptoms. ${ }^{21}$

Staff in services for adults with intellectual disabilities seem to be at no higher risk of burnout compared to staff in other caring services according to a systematic review. ${ }^{15}$ However, those staff most vulnerable to developing burnout tend to be the workers most valued by the services and burnout often indicates poor organizational support. 15

Resilience (hardiness) is a personality trait which may moderate the relationship between work demands and work related quality of life. 22 It has been described as a set of personality characteristics that function as resources to draw upon when encountering stressful demands. ${ }^{22}$ The key elements are control, commitment and challenge. Research with social workers has suggested that older individuals may well have a more effective and mature repertoire of coping styles. ${ }^{23}$

In this study, we describe the self-reported experience of work related quality of life and resilience among caring staff in the national Norwegian ID offender services. Local community based services are compared with their counterparts who are institutionally based. While the institutional staff emphasize the assessment and initial treatment issues during the acute period, the local community staff have to cope with lasting and more pervasive needs alongside the challenges of social integration.

Given these differences, the purpose of this study therefore was to compare the staff in ID offender institutional services to the staff in similar local community services in terms of professional quality of life and resilience.

\section{Materials and Methods}

\section{Setting and participants}

The study was conducted in 2012 among staff in the Norwegian National Unit for Mandatory Care. The penal code was set in 2002 , and at the time of data collection, 10 offenders with ID were serving a sentence. Nine of these had a local community placement and one was incarcerated at the institution for assessment and treatment planning. The institutional setting also serves as a custody unit for ID offenders/alleged offenders.

A total number of 106 staff members were given a set of questionnaires covering professional quality of life, and resilience. The response rate was high (80\%) with 85 completed questionnaires returned; 69 were from the locally based services and 16 from the institutional setting. The participants (36 women, 49 men) had a modal age category of 40-45. There were 38 registered nurses $(45 \%$ of the sample), 15 licensed practical nurses (18\%), and 25 unqualified staff (29\%). Seven (8\%) were professionals from other professions or students. The mean length of work experience within ID forensic services was 2.56 years (standard deviation=1.0). These demographic data was based on aggregated information from each setting rather than individual data in order to maintain confidentiality.

\section{Instruments}

Two self-administered questionnaires were used. A short registration form to obtain some basic demographic and occupational data was also distributed with these questionnaires.

Assessments of professional quality of life were made using the Professional Quality of Life Scale (ProQ0L). ${ }^{18}$ ProQ0L is a 30 item self-report measure designed to assess the following dimensions: compassion satisfaction, burn-out and compassion fatigue. The compassion satisfaction dimension (CS) measures the degree of pleasure derived from being able to do one's work well. High scores represent greater satisfaction related to this ability to be an effective caregiver. The burnout dimension (BO) in this scale is associated with feelings of hopelessness and difficulties in dealing with work demands. Higher scores indicate a higher severity of burnout. The compassion fatigue dimension (CF) relates to secondary exposure to extremely stressful work-related events (e.g. experiencing the trauma of someone one helped, even to the extent of avoiding activities to avoid reminders of the trauma). High scores on this dimension indicate significant exposure to frightening experiences at work. The alpha reliabilities for the scales of the ProQ0L have been found to be high: $\alpha=0.88$ (CS), 0.75 (B0) and 0.81 (CF). The construct validity is good with over 200 published papers. ${ }^{18} \mathrm{~A}$ Norwegian translation of the ProQ0L was used in the study. 24

Resilience was measured using a Norwegian version of the Dispositional Resiliency Scale (DRS). ${ }^{25}$ The DRS is recognized as the best available measure of hardiness, ${ }^{26}$ and the Norwegian version is based on Bartone's short 15-item version (DRS-15). ${ }^{27}$ The DRS-15 consists of 15 statements requiring respondents to indicate agreement on a 4-point scale (not at all true to completely true). To create hardiness scores, six negatively keyed statements are reversed, and all items are added. In addition to a total score, three subscale scores can be creat- ed by adding the relevant five items for each of the facets: commitment, challenge, and control. The alpha reliability of the total resilience score of the Norwegian version have been found to be $\alpha=0.79 .25$

\section{Procedure and ethics}

All executives in the local units and the institution were informed about the study and gave consent for their service to be accessed. The questionnaires were then sent to the executives for onward distribution to their staff members. The executives collected the completed questionnaires and returned them to the research group. The Regional Committee for Medical and Health Research Ethics approved the study (reference 2011/1321).

\section{Results}

The sample was divided into two comparative groups; staff in the local community services $(n=69)$ and staff in the institutional services $(n=16)$. The institutional group tended to be slightly younger with higher proportions of male and qualified staff (Table 1).

In both groups the respondents scored very similarly to the instrument norms for all three PROQ0L subscales (Figures 1-3). The total score of the DSR is also presented in a boxplot, although no norms were found in the literature (Figure 4).

Independent t-tests were conducted to compare scores on the measures in the two groups (Table 2). No significant differences were found for any of the PROQOL subscales but overall resilience and perceived control were significantly higher in the community staff group.

The internal consistency of the PROQOL subscales and total resilience (DRS-15) was high (Cronbach's alpha: $\mathrm{CS}=0.83, \mathrm{~B} 0=0.70$ $\mathrm{CF}=0.74$ for $\mathrm{CF}, \mathrm{DRS}=0.74$ ).

\section{Discussion and Conclusions}

The staff participating in this study were compared according to the nature of their relationship with the ID offender. The institutional and the local community services are inter-

Table 1. Age structure, qualification and gender in the compared groups.

\begin{tabular}{lccc} 
& Modal age group & $\begin{array}{c}\text { Qualification } \\
\text { as nurses }\end{array}$ & $\begin{array}{c}\text { Male/female } \\
\text { proportion }\end{array}$ \\
Institution staff $(\mathrm{n}=16)$ & 35 -39 years & $57 \%$ & $82 / 18$ \\
Community staff $(\mathrm{n}=69)$ & $45-49$ years & $45 \%$ & $54 / 46$ \\
\hline
\end{tabular}


linked but they are distinct in several respects as described in the introduction.

There were no significant differences between the local community staff and the institutional staff on any of the PROQOL subscales. This may be due to low statistical power, especially with regard to the small group of institutional staff. The scores were close to the normative data derived from extensive studies of 1187 people who worked in various helping professions. ${ }^{18}$ Although not significant, the results suggested somewhat greater compassion satisfaction alongside lower burnout symptoms and fatigue among the institutional staff. This may relate to the differing mandates of the two groups. Local community staff have a more stable relationship with the offender and his or her natural environment. Their capacity to focus on a single person may enable a stronger relationship to develop. The more technical and procedural approach to treatment in the institutional setting may set up a more cognitive, less emotional relationship.

Different ways of working in the two settings may also explain the differences in resilience (DRS-15), some of which were statistically significant. The Control subscale indicated a significantly greater sense of control in the community group, and this may reflect greater independence in working practices among local community staff. Institutions are often more focused on routines, rules and hierarchical systems compared to local services where emphasis is more directed to the service users. The community staff consequently would be expected more often to trust his/her own evaluations. The normative data for the Norwegian DSR-15 was based on a sample of military cadets and indicated a mean of 30.03 , (standard deviation=4.42). ${ }^{28}$ Both groups in the present study scored within these norms suggesting unremarkable levels of resilience.

Looking specifically at the community staff, they are older, less educated and had higher proportions of women. The higher scores on

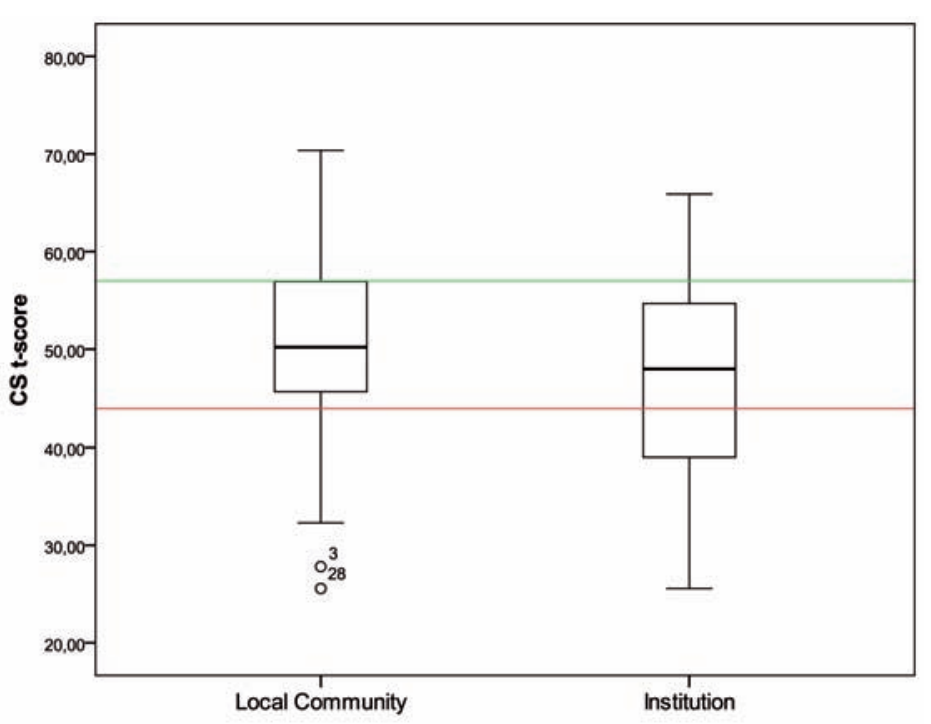

Figure 1. Box plot indicating median, quartiles and extreme values for scores on compassion satisfaction dimension (CS) at the two groups. Horizontal colored lines indicate bottom quartile and top quartile from normative data in the Professional Quality of Life Scale manual.

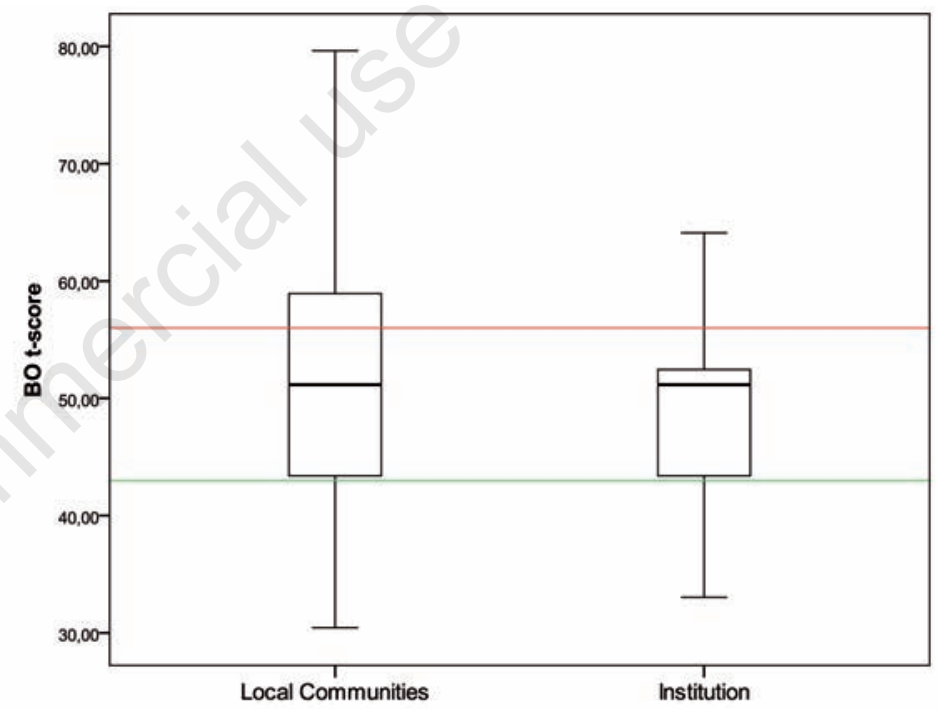

Figure 2. Box plot indicating median, quartiles and extreme values for scores on burnout dimension (BO) at the two groups. Horizontal colored lines indicate bottom quartile and top quartile from normative data in the Professional Quality of Life Scale manual.

Table 2. Mean scores on Professional Quality of Life Scale subscales and Dispositional Resiliency Scale (total and subscales in community and institutional staff).

\begin{tabular}{|c|c|c|c|c|c|c|}
\hline & \multicolumn{2}{|c|}{$\begin{array}{c}\text { Institution staff } \\
\qquad(\mathrm{n}=16)\end{array}$} & \multicolumn{2}{|c|}{$\begin{array}{l}\text { Community staff } \\
\qquad(\mathrm{n}=69)\end{array}$} & \multirow[t]{2}{*}{ Total (df) } & \multirow[t]{2}{*}{ P-value } \\
\hline & Mean & SD & Mean & SD & & \\
\hline ProQOL compassion satisfaction & 47.1 & 11.3 & 50.7 & 9.6 & $1.28(83)$ & 0.20 \\
\hline ProQOL burnout symptoms & 48.4 & 8.0 & 50.4 & 10.4 & $0.71(83)$ & 0.48 \\
\hline ProQOL compassion fatigue & 48.1 & 7.9 & 50.4 & 10.4 & $0.84(83)$ & 0.40 \\
\hline $\begin{array}{l}\text { DRS resilience total } \\
\text { DRS commitment } \\
\text { DRS control } \\
\text { DRS challenge }\end{array}$ & $\begin{array}{c}31.6 \\
11.0 \\
10.9 \\
9.6\end{array}$ & $\begin{array}{l}4.9 \\
1.9 \\
2.5 \\
2.4\end{array}$ & $\begin{array}{l}33.9 \\
11.7 \\
12.2 \\
10.0\end{array}$ & $\begin{array}{l}4.3 \\
2.0 \\
2.0 \\
2.2\end{array}$ & $\begin{array}{l}1.9(81) \\
1.3(81) \\
2.19(81) \\
0.53(81)\end{array}$ & $\begin{array}{l}0.06 \\
0.20 \\
0.03 \\
0.60\end{array}$ \\
\hline
\end{tabular}

DRS, dispositional resiliency scale; ProQOL, professional quality of life scale; SD, standard deviation. 
control subscale. It may be worth interviewing

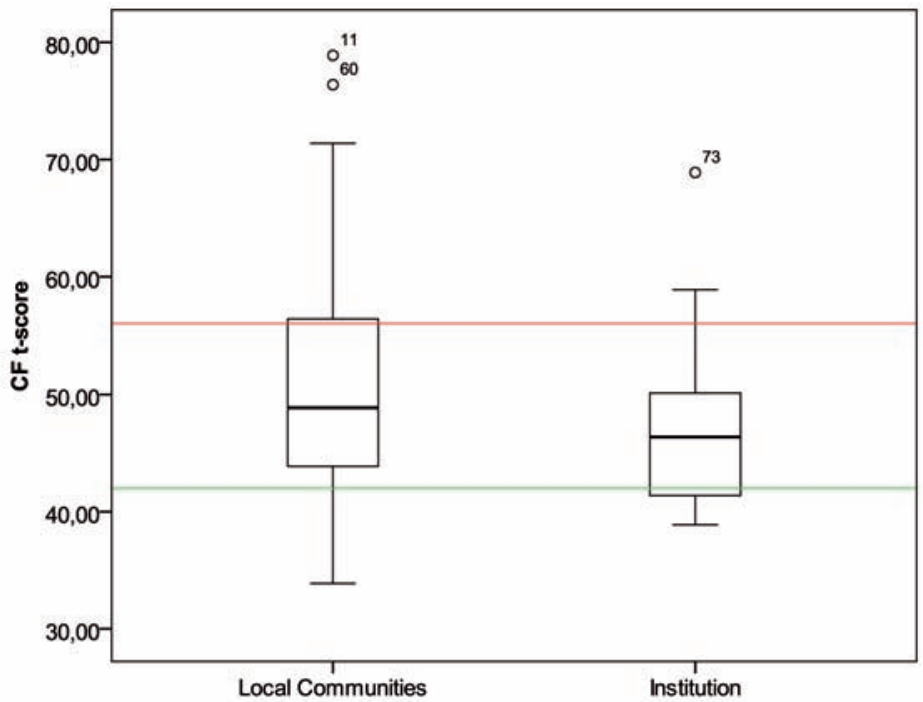

community staff about their coping strategies which might underpin such greater resilience and then conveying these strategies to their colleagues in the institutional setting thus potentially improving job satisfaction and care effectiveness.

\section{References}

1. Department of Occupational Health Surveillance. Psykososialt arbeidsmiljø [Psychosocial working environment], Stami-rapport nr. 2. 0slo: Statens Arbeidsmiljøinstitutt; 2008.

2. Svalund J. Vold og trusler om vold i offentlig sektor [Violence and threats in public services]. Oslo: FAF0; 2009.

Figure 3. Box plot indicating median, quartiles and extreme values for scores on compassion fatigue dimension (CF) at the two groups. Horizontal colored lines indicate bottom quartile and top quartile from normative data in the Professional Quality of Life Scale manual.

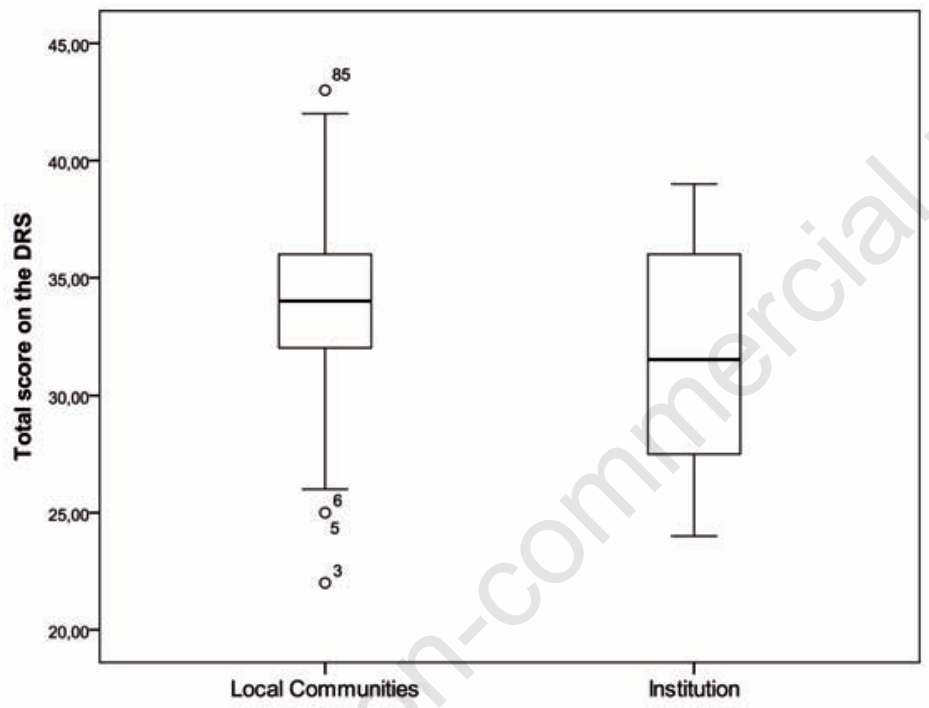

Figure 4. The Dispositional Resiliency Scale (DRS-15) underwent a similar box plot calculation to the Professional Quality of Life Scale subscales. The normative scores were not included in this figure.

resilient control in this group fit with previous findings about age.23 However the possible impact of gender or education on resilience in health care services has not been studied previously.

The response rate was very high for this sort of survey indicating that the sample is quite representative of the population of staff working with ID offenders. On the other hand, the relatively small institutional sample weakened the analysis and there was also comparison across groups unbalanced in size. The homogeneity of one institutional staff group com- pared to nine smaller and more differentiated community groups may also be a confounder.

This study was conducted in a sample of staff employed in the forensic services for people with ID. Further research should look at other groups working with challenging behavior in people with ID, or staff in forensic mental health services. A comparison between such larger and more defined groups could also been expedient.

In conclusion, a significant difference was found between staff in institutional and local settings in terms of overall resilience and the
3. Needham I, Abderhalden C, Halfens RJ, et al. The impact of patient aggression on carers scale: instrument derivation and psychometric testing. Scand J of Car Sci 2005;19:296-300.

4. Whittington R, Wykes T. Staff strain and social support in a psychiatric hospital following assault by a patient. J of Adv Nurs 1992;17:480-6.

5. Lindsay WR, Sturmey P, Taylor J. Natural history and theories of offending in people with developmental disabilities. In: Lindsay WR, Taylor J, Sturmey P, editors. Offenders with Developmental Disabilities. Chichester: Wiley; 2004.

6. Barron S, Hassiotis A, Banes J. Offenders with intellectual disability: a prospective comparative study. J Int Dis Res 2004; 48:69-76.

7. Holland T, Clare ICH, Mukhopadhyay T. Prevalence of criminal offending by men and women with intellectual disability and the characteristics of offenders: implications for research and service development. J Int Dis Res 2002;46:6-20.

8. Anderson G. People with intellectual disabilities who offend or are alleged to have offended. Assessing adults with intellectual disabilities. The British Psychological Society and Blackwell Publishing Ltd; 2008. pp 86-97.

9. Winter N, Holland T. Factors predisposing to suspected offending by adults with selfreported learning disabilities. Psychol Med 1997;27:595-607.

10. Emerson E. Challenging behaviour: analysis and intervention in people with learning disabilities. Cambridge: Cambridge University Press; 1995.

11. Søndenaa E, Rasmussen K, Palmstierna T, Nøttestad J. The prevalence and nature of intellectual disability in Norwegian prisons. J Int Disab Res 2008;52:1129-37.

12. Ministry of Justice. Straff som virker, min- 
dre kriminalitet, tryggere samfunn [Effective sanctions, less criminality, a safer community]. Oslo: Policedep; 2008.

13. Ministry of Justice. Straffeloven [The general civil penal code]. Oslo: Policedep; 2006.

14. Mutkins E, Brown RF, Thorsteinsson EB. Stress, depression, workplace and social supports and burnout in intellectual disability support staff. J Int Disab Res 2011;55:500-10.

15. Skirrow P, Hatton C. Burnout amongst direct care workers in services for adults with intellectual disabilities: a systematic review of research findings and initial normative data. J Appl Res Intellect 2007; 20:131-44.

16. Alexander M, Hegarty JR. Measuring staff burnout in a community home. Brit J Dev Disabil 2000;46:51-62.

17. White P, Edwards N, Townsend-White C. Stress and burnout amongst professional carers of people with intellectual disabili- ty: another health inequity. Curr Opin Psychiatr 2006;19:502-710.

18. Stamm BH. The Concise ProQOL manual 2010. Available from: http:/www.isu.edu/ bhstamm

19. Maslach C, Schaufeli WB, Leiter MP. JOB BURNOUT. Ann Rev Psychol 2001;52:397422.

20. Hastings RP, Horne S. Positive perceptions held by support staff in the community mental retardation services. Am J Ment Retard 2004;109:53-62.

21. Lawson DA, O'Brien R. Behavioral and self-report measures of staff burnout in developmental disabilities. J Org Behav Manage 1994;14:37-54.

22. Kobasa SC, Maddi SR, Puccetti MC. Personality and exercise as buffers in the stress-illness relationship. J Behav Med 1982;5:391-404.

23. Soderstrom M, Dolbier C, Leiferman J, Steinhardt M. The relationship of hardiness, coping strategies, and perceived stress to symptoms of illness. J Behav Med 2000;23:311-28.

24. Lauvrud C, Nonstad K, Palmstierna T, Occurence of post traumatic stress symptoms and their relationship to professional quality of lilfe (ProQOL) in nursing staff at a forensic psychiatric security unit: a cross sectional study. Health Qual Life Outc 2009;7:31.

25. Hystad SW, Eid J, Johnsen BH, et al. Psychometric properties of the revised Norwegian dispositional resilience (hardiness) scale. Scand J Psychol 2010;51:237-45.

26. Funk SC. Hardiness - a review of theory and research. Health Psychol 1992;11:335-45.

27. Bartone PT. A short hardiness scale. Paper presented at the Annual Convention of the American Psychological Society. New York, 1995.

28. Bartone PT, Johnsen BH, Eid J, et al. International adaptation of a brief human resiliency (hardiness) scale. Presented at the Association of the military surgeons of the US annual meeting. Texas, 2008. 